\title{
ANALISIS INDEKS MASA TUBUH (IMT) DENGAN TEKANAN DARAH PADA MAHASISWA STIKES MAMBA'UL 'ULUM SURAKARTA
}

\author{
Analysis Of Body Pressure (BMI) With Blood Pressure On Students \\ STIKES Mamba'ul 'Ulum Surakarta \\ Joko Tri Atmojo $^{1}$, Lilik Hanifah ${ }^{2}$, Catur Setyorini ${ }^{3}$ \\ STIKES Mamba'ul Ulum Surakarta \\ Jokotriatmojo1@gmail.com
}

\begin{abstract}
ABSTRAK
Latar Belakang: Permasalahan gizi pada orang dewasa cenderung didominasi oleh kelebihan berat badan. Indeks massa tubuh (IMT) merupakan alat yang sederhana untuk memantau status gizi orang dewasa yang berkaitan dengan kekurangan dan kelebihan berat badan, dimana Peningkatan berat badan memainkan peranan penting pada mekanisme timbulnya hipertensi pada orang dengan obesitas

Tujuan Penelitian: Mengetahui hubungan Indeks Masa Tubuh (IMT) Dengan Tekanan Darah Pada Mahasiswa STIKES Mamba'ul 'Ulum Surakarta

Metode: Desain pada penelitian ini adalah deskriptif dengan pendekatan cross sectional. Populasi dalam penelitian ini adalah semua mahasiswa STIKES Mamba'ul 'Ulum Surakarta, dengan Teknik sampling yang digunakan adalah accidental sampling, dimana jumlah sampel 68 orang. Alat yang digunakan dalam penelitian ini adalah pengukur tekanan darah digital, timbangan berat badan, pengukur tinggi badan dan lembar observasi. Analisis Data menggunakan Chi Square.

Hasil: Sebagian besar responden dengan IMT normal sebanyak 36 responden (52,9\%). Sebagian besar responden dengan Tekanan Darah normal sebanyak 54 responden $(79,4 \%)$. Ada hubungan yang signifikan antara Indeks Massa Tubuh dengan Tekanan Darah, dengan nilai p sebesar 0,040 dan nilai taraf signifikansi 0,05 maka dapat diketahui bahwa nilai $\mathrm{p}<0,05(0,040<0,05)$
\end{abstract}

Simpulan: Ada hubungan Indeks Masa Tubuh (IMT) Dengan Tekanan Darah Pada Mahasiswa STIKES Mamba’ul 'Ulum Surakarta

Kata Kunci: Indeks Massa Tubuh, Tekanan Darah, Mahasiswa

\begin{abstract}
Background: Nutritional problems in adults tend to be dominated by being overweight. Body mass index (BMI) is a simple tool for monitoring the nutritional status of adults in relation to underweight and overweight, wherein weight gain plays an important role in the mechanism of the emergence of hypertension in obese people.
\end{abstract}


Research purposes: Knowing the relationship between Body Mass Index (BMI) and Blood Pressure in STIKES Mamba'ul 'Ulum Surakarta Students.

Methods: The design in this study was descriptive with a cross sectional approach. The population in this study were all students of STIKES Mamba'ul 'Ulum Surakarta, with the sampling technique used was accidental sampling, where the sample size is 68 people. The instrument used in this study was a digital blood pressure meter, weight scales, height meter and observation sheet.

Results: Most of the respondents with normal BMI were 36 respondents (52.9\%). Most of the respondents with normal blood pressure were 54 respondents (79.4\%). There is a significant relationship between Body Mass Index and Blood Pressure, with a p value of 0.040 and a significance level of 0.05 , it can be seen that the $p$ value $<0.05(0.040<0.05)$.

Conclusion: There is a relationship between Body Mass Index (BMI) and Blood Pressure in STIKES Mamba'ul 'Ulum Surakarta Students

Keywords: Body Mass Index, Blood Pressure, Student

\section{PENDAHULUAN}

Berdasarkan data WHO (World Health Organization) diperkirakan penderita hipertensi diseluruh dunia berjumlah 600 juta orang, dengan 3 juta kematian setiap tahun. Hipertensi merupakan penyebab kematian nomor 3 setelah stroke dan tuberkulosis, sebesar 6,8 \% dari proporsi penyebab kematian pada semua umur di Indonesia (Malope, 2012).

Menurut data Riskesdas 2018, sebanyak 34,1\% masyarakat Indonesia dewasa umur 18 tahun keatas terkena hipertensi. Angka ini mengalami peningkatan sebesar 7,6 persen dibanding dengan hasil Riskesdas tahun 2013 yaitu 26,5\%. Selain itu prevelensi hipertensi naik dari 25,8 \% pada tahun 2013 menjadi 34,1\% pada tahun 2018. Sedangkan prevalensi hipertensi pada kelompok usia 18-39 tahun telah mencapai angka 7,3\% dan prevelensi pre-hipertensi pada kelompok usia tersebut mencapai angka yang cukup tinggi yaitu 23,4\%. (Kemenkes RI, 2018)

Hipertensi sering diartikan sebagai suatu keadaan dimana tekanan darah sistolik lebih dari $120 \mathrm{mmHg}$ dan tekanan diastolik lebih dari $80 \mathrm{mmHg}$ (Ardiansyah, 2012). Meningkatnya tekanan darah dapat dipengaruhi oleh banyak faktor diantaranya keturunan, kegemukan, kurangnya aktifitas, dan lain sebagainya. Hipertensi yang tidak terkontrol, maka baik secara langsung maupun tidak langsung dapat menimbulkan kerusakan organ. Kerusakan organ tersebut akan mempengaruhi prognosis pasien hipertensi. (Yogiantoro, 2010)

Hasil beberapa penelitian menggambarkan bahwa hipertensi yang tidak terkontrol dapat meningkatkan peluang terjadinya stroke 7 kali lebih besar, 6 kali lebih besar terkena congestive heart failure, dan 3 kali lebih besar terkena serangan jantung. (Rahajeng dan Tuminah, 2009) 
Permasalahan gizi pada orang dewasa cenderung didominasi oleh kelebihan berat badan. Saat ini terdapat berbagai metode pengukuran antropometri tubuh yang dapat digunakan sebagai skreening obesitas. Metode tersebut antara lain pengukuran indeks massa tubuh, lingkar pinggang, lingkar panggul, lingkar lengan atas, serta perbandingan lingkar pinggang dan lingkar panggul (Malope, 2012).

Indeks massa tubuh (IMT) merupakan alat yang sederhana untuk memantau status gizi orang dewasa khususnya yang berkaitan dengan kekurangan dan kelebihan berat badan. Penggunaan IMT hanya berlaku untuk orang dewasa berumur diatas 18 tahun. IMT tidak dapat diterapkan pada bayi, anak, remaja, ibu hamil dan olahragawan. Indikator obesitas pada dewasa yaitu pada orang dengan indeks massa tubuh (IMT) diatas 27,0. Dimana IMT normal berada pada angka 18,5 sampai 22,9. (Supariasa, 2012).

Hasil Riskesdas (2018) menyatakan prevalensi obesitas pada orang dewasa di atas 18 tahun terus meningkat sejak tiga periode Riskesdas yaitu tahun 2007 sejumlah 10,5\%, tahun 2013 sejumlah 14,8\% dan tahun 2018 meningkat menjadi 21,8\%. Peningkatan obesitas penduduk Indonesia ini juga diikuti dengan peningkatan pola hidup tidak sehat yang dilakukan oleh masyarakat Indonesia, seperti prevalensi merokok pada remaja usia 10-18 tahun meningkat menjadi $9,1 \%$, proporsi konsumsi minuman beralkohol meningkat menjadi 3,3\%, proporsi aktivitas fisik kurang naik menjadi 33,5\% dan proporsi konsumsi buah dan sayur kurang pada penduduka diatas lima tahun masih 95,5\%. (Kemenkes RI, 2018)

Peningkatan berat badan memainkan peranan penting pada mekanisme timbulnya hipertensi pada orang dengan obesitas, hal ini sejalan dengan penelitian yang dilakukan oleh Marlina dkk (2016) yang menunjukkan terdapat korelasi antara IMT dengan tekanan darah sistolik dan diastolic pada pelajar SMA di Pekanbaru. Setiap kenaikan IMT/U sebesar $1 \mathrm{~kg} / \mathrm{m} 2$ diprediksikan dapat meningkatkan nilai tekanan darah sistolik dan diastolik masing-masing sebesar 2,339 $\mathrm{mmHg}$ dan $0,979 \mathrm{mmHg}$.

Penelitian ini juga didukung oleh penelitian dari Shaumi dan Achmad, 2019) bahwa terdapat beberapa faktor risiko yang berhubungan dengan kejadian hipertensi pada remaja di Indonesia. Kualitas tidur, IMT/U, dan riwayat hipertensi keluarga berpengaruh secara bermakna terhadap kejadian hipertensi pada remaja. Remaja dengan kualitas tidur yang buruk memiliki risiko 4,1 kali lebih besar, IMT/U yang tinggi memiliki risiko 4,85 kali lebih besar, dan riwayat hipertensi keluarga memiliki risiko 3,9 kali lebih besar untuk mengalami hipertensi. IMT/U merupakan faktor dominan terhadap risiko hipertensi pada remaja.

Kejadian peningkatan tekanan darah pada anak seringkali tidak terdeteksi sejak dini sehingga menetap hingga usia dewasa yang menyebabkan hipertensi bahkan penyakit jantung koroner. Hal ini dipicu oleh kejadian peningkatan berat badan pada anak. Berdasarkan uraian permasalahan tersebut, perlu dilakukan penelitian untuk melihat Analisis Indeks Massa Tubuh (IMT) dengan Tekanan Darah pada Mahasiswa STIKES Mamba'ul Ulum Surakarta. 


\section{METODE}

Desain penelitian adalah penelitian deskriptif dengan pendekatan cross sectional. Variabel bebas dalam penelitian ini adalah Indeks Massa Tubuh (IMT), Variabel Terikat dalam penelitian ini adalah Tekanan Darah. Populasi dalam penelitian ini adalah semua mahasiswa STIKES Mamba'ul 'Ulum Surakarta. Teknik sampling yang digunakan adalah accidental sampling. Sampel dalam penelitian ini adalah mahasiswa STIKES Mamba'ul 'Ulum Surakarta pada saat pelaksanaan posbindu Bulan Februari 2020 yaitu 68 orang. Alat yang digunakan dalam penelitian ini adalah pengukur tekanan darah digital, timbangan berat badan, pengukur tinggi badan, lembar observasi yang berisi hasil pengukuran tekanan darah, pengukuran berat badan dan tinggi badan.

Metode pengumpulan data dengan menggunakan data sekunder, yang berupa hasil pemeriksaan BB, IMT, dan TD pada bulan Februari 2020. Analisis Data menggunakan Chi Square dengan Stastitical Product Servise Solution (SPSS) versi 17.

\section{HASIL DAN PEMBAHASAN}

\section{Hasil}

1. Karakteristik responden berdasarkan Indeks Masa Tubuh (IMT)

Tabel 1 Distribusi frekuensi karakteristik responden berdasarkan IMT

\begin{tabular}{cccc}
\hline No & IMT & Frekuensi & Prosentase(\%) \\
\hline 1 & Kurus & 18 & 26,5 \\
2 & Gemuk & 14 & 20,6 \\
3 & Normal & 36 & 52,9 \\
& Jumlah & 68 & 100 \\
\hline
\end{tabular}

Sumber: Data primer 2020

Berdasarkan tabel 1 di atas sebagian besar responden dengan IMT Normal sebanyak 36 responden $(52,9 \%)$.

2. Karakteristik responden berdasarkan Tekanan Darah (TD)

Tabel 2 Distribusi frekuensi karakteristik responden berdasarkan TD

\begin{tabular}{cccc}
\hline No & IMT & Frekuensi & Prosentase(\%) \\
\hline 1 & Hipotensi & 9 & 13,2 \\
2 & Hipertensi & 5 & 7,4 \\
3 & Normal & 54 & 79,4 \\
& Jumlah & 68 & 100 \\
\hline
\end{tabular}

Sumber: Data primer 2020

Berdasarkan tabel 2 di atas sebagian besar responden dengan Tekanan Darah Normal sebanyak 54 responden $(79,4 \%)$. 
3. Analisis Data Indeks Masa Tubuh (IMT) dengan Tekanan Darah (TD)

Tabel 3. Analisis Indeks Masa Tubuh (IMT) dengan Tekanan Darah (TD) pada Mahasiswa

\begin{tabular}{|c|c|c|c|c|c|c|c|c|c|}
\hline \multirow[t]{3}{*}{ IMT } & \multicolumn{6}{|c|}{ Tekanan Darah } & \multirow[t]{3}{*}{ Total } & \multirow[t]{3}{*}{$\%$} & \multirow{3}{*}{$\begin{array}{l}\text { Analisis } \\
\text { Chi Square }\end{array}$} \\
\hline & \multicolumn{2}{|c|}{ Hipotensi } & \multicolumn{2}{|c|}{ Hipertensi } & \multicolumn{2}{|c|}{ Normal } & & & \\
\hline & $\mathrm{F}$ & $\%$ & $\mathrm{~F}$ & $\%$ & $\mathrm{~F}$ & $\%$ & & & \\
\hline Kurus & 3 & 33,3 & 2 & 40 & 11 & 20,4 & 18 & 26,5 & Significant \\
\hline Gemuk & 1 & 11,1 & 1 & 20 & 13 & 24,1 & 14 & 20,6 & 0,040 \\
\hline Normal & 5 & 55,6 & 2 & 40 & 30 & 55,5 & 36 & 52,9 & \\
\hline Jumlah & 9 & 100 & 5 & 100 & 54 & 100 & 100 & 100 & \\
\hline
\end{tabular}

Sumber: Data primer 2020

Pada Tabel 3. menunjukkan mayoritas responden memiliki status IMT Normal dengan Tekanan Darah Normal sebanyak 30 responden $(55,5 \%)$.

Berdasarkan hasil uji chi - square di lihat dari nilai p sebesar 0,040 dan nilai taraf signifikansi 0,05 maka dapat diketahui bahwa nilai $\mathrm{p}<0,05(0,040<$ $0,05)$, sehingga kesimpulannya ada hubungan yang signifikan antara Indeks Massa Tubuh dengan Tekanan Darah.

\section{Pembahasan}

Pada hasil penelitian diperoleh hasil bahwa mayoritas Indeks Massa Tubuh (IMT) adalah normal. Indeks masa tubuh merupakan pengukuran berat badan dan tinggi badan yang menggambarkan kadar lemak tubuh (Setyawati \& Hartini, 2018). Indeks masa tubuh diatas normal sering mengakibatkan berbagai macam penyakit diantaranya penyakit jantung dan pembuluh darah, diabetes mellitus, kanker, osteoartritis dan juga penyakit hipertensi (Ardania, 2012).

Sekitar $65-75 \%$ penyebab hipertensi paling banyak disebabkan oleh faktor resiko Indeks Masa Tubuh diatas normal. Peningkatan tekanan darah terjadi karena adanya peningkatan reabsorpsi di tubular ginjal, sehingga mengakibatkan tekanan natriuresis rusak dan terjadi ekspansi volume karena aktivasi oleh Sistem saraf simpatik dan sistem renin-angiotensi aldosteron dan akibat terjadi tekanan fisik di ginjal yang diakibatkan oleh obesitas viseral(Hall M., et all, 2014).

Hasil penelitian menunjukkan mayoritas mahasiswa dengan Tekanan Darah normal, dimana untuk usia mahasiswa adalah sekitar $19-20$ tahun. Menurut (Lionakis, et all, 2012), usia merupakan bagian dalam kehidupan yang tidak dapat dipungkiri bisa menyebabkan dua hal yang tidak menyenangkan yaitu penurunan fisiologis tubuh dan rentan terhadap penyakit. Insiden hipertensi paling sering terjadi pada usia lansia diatas 65 tahun (Buford, 2016). Pertambahan usia menyebabkan struktur pembuluh darah menjadi sempit dan dinding pembuluh darah menjadi kaku sehingga terjadi peningkatan tekanan darah (Novitaningsih, 2014)

Berdasarkan hasil analisis menunjukkan bahwa ada hubungan Indeks Massa Tubuh (Tubuh) dengan Tekanan Darah, Peningkatan berat badan memainkan peranan penting pada mekanisme timbulnya hipertensi, hal ini sejalan dengan 
penelitian yang dilakukan oleh Marlina dkk (2016) yang menunjukkan terdapat korelasi antara IMT dengan tekanan darah sistolik dan diastolic pada pelajar SMA di Pekanbaru. Setiap kenaikan IMT/U sebesar $1 \mathrm{~kg} / \mathrm{m} 2$ diprediksikan dapat meningkatkan nilai tekanan darah sistolik dan diastolik masing-masing sebesar 2,339 $\mathrm{mmHg}$ dan $0,979 \mathrm{mmHg}$.

Hasil penelitian ini sesuai dengan hasil penelitian dari (Tendean. A.F. 2019) dimana hasil penelitian yang didapat kategori Indeks masa tubuh terbanyak dalam kategori normal 48,3\%, kategori tekanan darah sistolik terbanyak kategori prehipertensi $53,9 \%$ dan kategori tekanan darah diastolik terbanyak kategori prehipertensi $34,8 \%$. Hasil analisa korelasi menggunakan spearman correlation didapati korelasi IMT dengan tekanan darah sistolik p 0,001<0,05 dengan $r=0,360$ dan korelasi IMT dengan tekanan darah diastolik p 0,000<0,05 dengan $r=0,389$. Kesimpulan ada hubungan yang signifikan antara IMT dengan tekanan darah sistolik maupun diastolik. Semakin meningkat IMT maka tekanan darah sistolik maupun diastolik akan meningkat.

Penelitian ini juga didukung oleh penelitian dari Shaumi dan Achmad, 2019) bahwa terdapat beberapa faktor risiko yang berhubungan dengan kejadian hipertensi pada remaja di Indonesia. Kualitas tidur, IMT/U, dan riwayat hipertensi keluarga berpengaruh secara bermakna terhadap kejadian hipertensi pada remaja. Remaja dengan kualitas tidur yang buruk memiliki risiko 4,1 kali lebih besar, IMT/U yang tinggi memiliki risiko 4,85 kali lebih besar, dan riwayat hipertensi keluarga memiliki risiko 3,9 kali lebih besar untuk mengalami hipertensi. IMT/U merupakan faktor dominan terhadap risiko hipertensi pada remaja.

Dalam hal ini penelitian ini juga sejalan dengan penelitian dari (Merdianti, dkk, 2019) dimana analisis menggunakan uji Chi Square dengan nilai signifikan $\leq$ 0,05 . Hasil menunjukkan bahwa status nutrisi dan gaya hidup terhadap tekanan darah remaja mempunyai korelasi dengan nilai $(\mathrm{p}=0,000)$. Kesimpulan dalam penelitian ini adalah bahwa terdapat hubungan korelasi antara status nutrisi dan gaya hidup terhadap tekanan darah pada remaja di Kelurahan Lidah Kulon Kota Surabaya. Penelitian selanjutnya diharapkan dapat menambah penelitian dengan deteksi kesehatan dini seperti penelitian ini terutama kepada generasi muda karena hal ini dapat menjadi masalah yang serius di masa depan.

Banyak kejadian hipertensi pada remaja yang diawali dengan kegemukan atau obesitas. Tekanan darah cenderung lebih tinggi pada orang yang gemuk atau obesitas daripada orang dengan berat badan normal. Pada obesitas tahanan perifer berkurang atau normal, sedangkan aktifitas saraf simpatis meninggi dengan aktifitas renin plasma yang rendah. (Kozier, 2011)

Indeks Massa Tubuh merupakan metode yang digunakan untuk menentukan status gizi seseorang. Penilaian status gizi pada remaja yaitu dengan menggunakan perhitungan IMT yang kemudian dicocokan dengan grafik pertumbuhan sesuai dengan usia dan jenis kelamin.Terdapat hubungan yang bermakna antara status gizi (IMT/U) dengan tekanan darah sistolik sedangkan status gizi (WHR) tidak terdapat hubungan dengan tekanan darah sistolik pada mahasiswa program studi 
pendidikan dokter angkatan 2013 Fakultas Kedokteran Universitas Sam Ratulangi (Yulyius, 2013)

Penelitian di Depok (2017) menggunakan uji Chi-square dan uji regresi logistik ganda menganalisis hubungan IMT/U, asupan zat gizi mikro (natrium, kalium, dan kalsium), stres, jenis kelamin dan riwayat hipertensi keluarga. Hasil uji menggunakan uji Chi-square menunjukkan faktor risiko IMT/U memiliki $p$ value $=0,001$ dan hasil uji regresi logistik ganda memiliki $p$ value $=0,005$. Kedua nilai tersebut menunjukkan bahwa IMT/U berhubungan dan memiliki pengaruh terhadap kejadian hipertensi pada remaja. Hasil uji regresi logistik ganda menunjukkan nilai Odds Ratio (OR) pada remaja dengan gizi lebih sebesar 3,51 (95\% CI 1,420-7,094). Nilai tersebut menunjukkan bahwa remaja dengan status gizi lebih memiliki risiko 3,51 kali untuk mengalami hipertensi dibandingkan dengan remaja yang memiliki status gizi normal (Angesti AN, Triyanti, Sartika RAD, 2017)

\section{Simpulan}

\section{SIMPULAN DAN SARAN}

Berdasarkan hasil penelitian dapat disimpulkan bahwa Sebagian besar responden dengan IMT normal sebanyak 36 responden (52,9\%). Sebagian besar responden dengan Tekanan Darah normal sebanyak 54 responden $(79,4 \%)$. Ada hubungan yang signifikan antara Indeks Massa Tubuh dengan Tekanan Darah. Hal ini ditunjukkan dengan nilai p sebesar 0,040 dan nilai taraf signifikansi 0,05 maka dapat diketahui bahwa nilai $\mathrm{p}<0,05(0,040<0,05)$

\section{Saran}

Saran yang dapat diberikan dalam penelitian ini adalah diharapkan mahasiswa untuk menjaga pola makan dan gaya hidup sehat, untuk menjaga Indeks Massa Tubuh (IMT) dan Tekanan Darah dalam keadaan normal sejak remaja. Diharapkan peneliti selanjutnya dapat meneliti tentang faktor - faktor yang mempengaruhi Tekanan darah seperti usia, kondisi fisik, dll sehingga dapat diketahui faktor yang paling berpengaruh terhadap Tekanan Darah. Diharapkan STIKES Mamba'ul 'Ulum Surakarta untuk rutin menyelenggarakan kegiatan Posbindu untuk mendeteksi kesehatan mahasiswa

\section{DAFTAR PUSTAKA}

Angesti AN, Triyanti, Sartika RAD. 2017. Riwayat Hipertensi Keluarga Sebagai Faktor Dominan Hipertensi pada Remaja Kelas XI SMA Sejahtera 1 Depok Tahun 2017. Bul Penelit Kesehat. 2018;46(1):1-10.

Ardania, S. (2012). Hubungan Indeks Masa Tubuh Dengan Tekanan Darah Pada Masyarakat Di Kelurhan Pakuncen Wirobrajan Yogyakarta. Program Studi Ilmu Keperawatan Sekolah Tinggi Ilmu Kesehatan 'Aisyiyah Yogyakarta, Naskah Publikasi.

Ardiansyah Muhammad. 2012. Medikal Bedah Untuk Mahasiswa. Jogjakarta: Diva Press. 
Buford, T. (2016). Hypertension and aging. Ageing Research Review.Vol.26, 96111. doi:10.1016/j.arr.2016.01.007.

Hall, M., do Carmo, J., da Saliva, A., Juncos, L., Wang, Z., \& Hall, J. (2014). Obesity, Hypertension And Chronic Kidney Disease. International Journal Of Nephrology And Renavascular Disease. Vol : 2014, 75 - 88. doi:10.2147/IJNRD.S39739.

Kementerian Kesehatan RI. 2018. Riset Kesehatan Dasar Tahun 2018. Jakarta : Kemenkes RI

Kozier. 2011. Buku Ajar Fundamental Keperawatan. Jakarta : EGC

Lionakis, N., Mendrinos, D., Sanidas, E., Favatas, G., \& Georgopoulou, M. 2012. Hypertension in the elderly. World Journal of Cardiology. Vol.4.No.5, 135147.doi:10.4330//wjc.V4.i5.135.

Malope Sheila. 2012. Hubungan Lingkar Lengan Atas dan Lingkar Pinggang dengan Tingkat Hipertensi pada Pasien Rawat Jalan di Poloklinik Interna RSJ Prof. Dr. V. L. Ratumbuysang Provinsi Sulawesi Utara.

Marlina, Yessi, dkk. 2016. Indeks massa tubuh dan aktivitas fisik dengan tekanan darah pada pelajar SMA di Pekanbaru. Jurnal Gizi Klinik Indonesia Vol 12 No 4

Merdianti. R, dkk. 2019. Hubungan status nutrisi dan gaya hidup terhadap tekanan dpada Remaja di Kelurahan Lidah Kulon Kota Surabaya. Jurnal Ners Dan Kebidanan. Volume 6, Nomor 2, Agustus 2019, hlm. 218-226. Universitas Airlangga Surabaya

Novitaningsih, T. (2014). Hubungan karakteristik (umur,jenis kelamin, tingkat pendidikan) dan aktivitas fisik dengan tekanan darah pada lansia di kelurahan makamhaji kecamatan Kartasura Kabupaten Sukohardjo. Program Studi Gizi Fakultas Ilmu Kesehatan Universitas Muhammadiyah Surakarta.Naskah publikasi

Rahajeng E, Tuminah S. 2009. Prevalensi Hipertensi dan Determinannya di Indonesia. Majalah Kedokteran Indonesia.

Setyawati, V., \& Hartini, E. (2018). Buku Ajar Dasar Ilmu Gizi Kesehatan Masyarakat. Ed.1.Yogyakarta: Deepublish.

Shaumi, NRF dan Achmad, EK. 2019. Kajian Literatur: Faktor Risiko Hipertensi pada Remaja di Indonesia. Jurnal Media Litbangkes, Vol. 29 No. 2.

Supariasa, Nyoman. 2012. Penilaian Status Gizi. Jakarta: EGC

Tendean, A. F. (2019). Korelasi Indeks Masa Tubuh (Imt) Dengan Tekanan Darah. Nutrix Journal, 3(2), 11-20.

Yogiantoro M. Hipertensi Esensial. 2010. Dalam: Sudoyo AW, Setiyohadi B, Alwi I, K Simanibrata M, Setiana S. Syam AF, dkk, editor. Buku Ajar Ilmu Penyakit Dalam. Edisi ke-5. Jakarta: Interna Publishing; 2010. h. 1079-85.

Yulyius, dkk. 2013. Hubungan Antara Status Gizi Dengan Tekanan Darah Mahasiswa Program Studi Pendidikan Dokter Angkatan 2013 Fakultas Kedokteran Universitas Sam Ratulangi. Vol 2 No 1 https://ejournal.unsrat.ac.id/index.php/ebiomedik/article/view/3696 